GA-A14291

UC-77

\title{
FLOW-INDUCED AND ACOUSTICALIY INDUCED VIBRATION EXPERIENCE \\ IN OPERATING GAS-COOLED REACTORS
}

by

L. J. Halvers

Prepared under

Contract EY-76-C-03-0167

Project Agreement No. 23

for the

San Francisco Operations Office

U.S. Energy Research and Development Administration

Thes report was prepatiCE an account of wotk Ths report whe United States Government. Netther the United States nor the United States Energy Research and Development Administration, nor any of their employees, nor any of theis contractors, subcontractors, or their employees. makes any warranty, express or impled, or assucs anplenes Labity or responathy or usefilness of infrnge privately owned rights. 


\section{DISCLAIMER}

This report was prepared as an account of work sponsored by an agency of the United States Government. Neither the United States Government nor any agency Thereof, nor any of their employees, makes any warranty, express or implied, or assumes any legal liability or responsibility for the accuracy, completeness, or usefulness of any information, apparatus, product, or process disclosed, or represents that its use would not infringe privately owned rights. Reference herein to any specific commercial product, process, or service by trade name, trademark, manufacturer, or otherwise does not necessarily constitute or imply its endorsement, recommendation, or favoring by the United States Government or any agency thereof. The views and opinions of authors expressed herein do not necessarily state or reflect those of the United States Government or any agency thereof. 


\section{DISCLAIMER}

Portions of this document may be illegible in electronic image products. Images are produced from the best available original document. 


\begin{abstract}
An overview has been presented of flow-induced and acoustically induced vibration fallures that occurred in the past in gas-cooled graphite-moderated reactors, and the importance of this experience for the Gas-Cooled FastBreeder Reactor (GCFR) project has been assessed. Until now only failures in $\mathrm{CO}_{2}$-cooled reactors have been found. No problems with helium-cooled reactors have been encountered so far. It is shown that most of the failures occurred because flow-induced and acoustically induced dynamic loads were underestimated, while at the same time not enough was known about the influence of environmental parameters on material behavior. Al1 problems encountered were solved.
\end{abstract}

The comparison in Appendix B of the influence of the gas properties on acoustically induced and flow-induced vibration phenomena shows that the interaction between reactor design and the thermodynamic properties of the primary coolant precludes a general preference for either carbon dioxide or helium. The acoustic characteristics of $\mathrm{CO}_{2}$ and He systems are different, but the difference in dynamic loadings due to the use of one rather than the other remains difficult to predict. A slight preference for helium seems, however, to be justified. 
CONTENTS

ABSTRACT . . . . . . . . . . . . . . . . . . . . . . 1

1. INTRODUCTION . . . . . . . . . . . . . . . . . . . . . 1

2. FLOW-INDUCED AND ACOUSTICALLY INDUCED VIBRATIONS . . . . . . . . . 3

2.1. Flow-Induced Vibrations . . . . . . . . . . . . 3

2.2. Acoustically Induced Vibrations . . . . . . . . . . 5

3. OVERVIEW OF REPORTED PROBLEMS . . . . . . . . . . . . . . . . 7

3.1. Experience in the United Kingdom . . . . . . . . . . . 7

3.2. Experience in Japan . . . . . . . . . . . . . . 15

3.2.1. Fatigue Failure of Tubes of Low Pressure Superheater Tube Bends Due to Vortex Shedding . . . . . . 15

3.2.2. Fracture of Splitter Plates and Fixing Bo1ts at Main Blower Outlet Bends . . . . . . . . . 15

3.2.3. Failure of Gas Circulator Inlet Bellows . . . . . 15

3.2.4. Breakaway of Insulation Cover Plates at Nozzles of Hot Gas Outlet Ducts . . . . . . . . . . 17

3.3. Experience in France . . . . . . . . . . . . . . 18

3.4. Experience in the United States . . . . . . . . . . . 21

3.5. Experience in Italy . . . . . . . . . . . . . . . 23

3.6. Experience in Germany . . . . . . . . . . . . . . 24

4. RELEVANCE OF THE EXPERIENCE FOR THE GCFR PROJECT . . . . . . . . . . 25

5. CONCLUSIONS . . . . . . . . . . . . . . . . . . 28

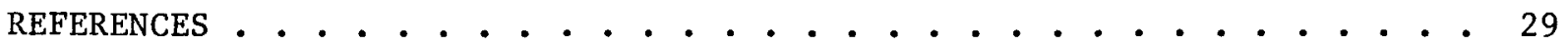

APPENDIX A. ACOUSTIC TERMS AND UNITS . . . . . . . . . . . . . . . A-1

APPENDIX B. COMPARISON OF THE INFLUENCE OF CARBON DIOXIDE AND HELIUM

GAS PROPERTIES ON ACOUSTICALLY INDUCED AND FLOW-INDUCED

VIBRATION PHENOMENA . . . . . . . . . . . . . . B-1 


\section{FIGURES}

1. Hinkley Point A Station - arrangement of gas circuit and components . . . . . . . . . . . . . . . . . . . 8

2. Dungeness A MAGNOX station . . . . . . . . . . . . . . 12

3. IMAI Station - arrangement of gas circuit and components . • . . 16

B-1. $R_{\mathrm{rad}}$ as a function of frequency for a flat $6 \mathrm{~m}^{2}, 0.005-\mathrm{m}$-thick plate in He and $\mathrm{CO}_{2}, n=0.034$. . . . . . . . . . . . B-10

B-2. $R_{\text {mech }}$ and $n_{\text {rad }}$ as a function of frequency for a flat plate in He and $\mathrm{CO}_{2}$......................... B-11

B-3. Relative response per unit sound pressure for a flat plate in $\mathrm{He}$ and $\mathrm{CO}_{2}$. . . . . . . . . . . . . . . . . . . B-12

\section{TABLES}

1. Reactor Characteristics - United Kingdom . . . . . . . . . . 9

2. Reactor Characteristics - Japan, Italy, Spain . . . . . . . . 19

3. Reactor Characteristics - France . . . . . . . . . . . . . 20

4. Reactor Characteristics - United States . . . . . . . . . 22

$\mathrm{B}-1$. Basic Properties of $\mathrm{He}$ and $\mathrm{CO}_{2}$ for Specified Reactor Conditions . . . . . . . . . . . . . . . . . . B-2

B-2. Primary Coolant Circulator Operating Conditions . . . . . . B B-5 


\section{INTRODUCTION}

In the early days of the development of the MAGNOX and advanced gascooled reactors (AGRs) a number of failures occurred which proved to be attributable to acoustically induced and flow-induced vibrations. These failures attracted much attention because they of ten caused long-term delays of the startup of the power stations. If any generalized reason for the delays can be given it is that design of components went ahead before enough was known of the environment in which they had to work. The environmental parameters of temperature, gas flows, noise, and others proved more destructive than anticipated, and the critical combinations of these parameters were not tested in experimental setups beforehand. Since those early days much has been learned. The purpose of this report is three-fold: first, to review the problems encountered in the past and their solutions; second, to determine the system parameters that govern acoustically induced and flow-induced vibrations; and last, to assess the significance of these findings for the GCFR design and development.

A report like this, in fact a compilation of failures, perhaps tends to give the impression that the GCFR may also be vulnerable to this kind of failure. It must be stressed that this is not by definition the case. To put things in perspective, most of the problems encountered were related to the progressive development of new technology in which the size of the components, the mass flows, etc., increased rapidly, and insufficient time was allowed to determine theoretically or experimentally the effect of the above-mentioned environmental parameters. The problems have since been solved satisfactorily, and a vast amount of experience has been obtained which is presently available. This experience, in combination with further theoretical analyses and experimental tests, will give the information required for a safe and reliable GCFR design. 
After a short description of the phenomena of flow-induced and acoustically induced vibrations in Chapter 2, an overview will be presented in Chapter 3 of reported failures, their most probable causes, and the measures taken to prevent recurrence. The relevance of this experience for the GCFR will be analyzed in Chapter 4, and the conclusions will be presented in Chapter 5 . 


\section{FLOW-INDUCED AND ACOUSTICALLY INDUCED VIBRATIONS}

\subsection{FLOW-INDUCED VIBRATIONS}

Flow-induced vibrations are random or periodic structural vibrations caused and sustained by gases or liquids flowing over solid structures. The dynamic interaction between the fluid and the structure is characterized by random or periodic changes in the interactive forces. A deformation in the structure or component induces a change in the fluid force on the structure which in turn generates an adjustment of the deformation to accommodate the new fluid force, etc. Hence, unsteady flow generates unsteady surface forces. Failures due to fatigue, fretting, or wear can occur if the flow conditions and the structural response combine in an unfavorable way. To analyze a situation with a potential for flow-induced vibration problems, the fluid forces on the structure must be identified and described. This proves to be difficult under the turbulent flow conditions which normally prevall in gas-cooled reactors. Consequently, one has to resort to empirical correlations and experimental results.

Vortex-induced vibrations caused by a steady external flow are probably among the best known flow-induced vibration phenomena. In this case periodic forces are exerted on the structure due to the vortices which are alternatively shed from each side of the structure. The fluctuating pressure field generates an oscillating force on the structure which can cause vibrations depending on system parameters such as the mass ratio of the structure and the fluid $\left(m / \rho D^{2}\right)$, the Reynolds number $(U D / \nu)$, the geometry of the structure $(\ell / D)$, the structural damping $(\zeta)$, and the reduced velocity (U/fD). 
According to Ref. 1 the dimensionless amplitude can be written as

$$
\frac{\mathrm{A}}{\mathrm{D}}=\mathrm{F}\left(\frac{\ell}{\mathrm{D}}, \frac{\mathrm{UD}}{\nu}, \frac{\mathrm{U}}{\mathrm{fD}}, \frac{\mathrm{m}}{\rho \mathrm{D}^{2}}, \zeta\right) \text {, }
$$

where $A=$ amplitude of vibration normal to the free stream, $m$,

$D=$ width of the flow obstacle, $m$,

$\ell=$ length of the flow obstacle, $m$,

$U=$ free stream velocity or velocity at minimum cross-section

for tube array, $\mathrm{m} / \mathrm{sec}$,

$\nu=$ kinematic viscosity, $\mathrm{m}^{2} / \mathrm{sec}$,

$\mathrm{f}=$ frequency of the structural vibration, $\mathrm{Hz}$,

$\mathrm{m}=$ mass of the structure per unit length, $\mathrm{kg} / \mathrm{m}$,

$\rho=$ fluid density, $\mathrm{kg} / \mathrm{m}^{3}$,

$\zeta=$ damping ratio of the structure, which is the energy dissipated per cycle divided by $4 \pi$ times the total energy of the structure.

In case the vortex shedding frequency is equal to one of the natural frequencies of the structure, the shedding frequency is synchronized with the structural vibration frequency and large amplitude vibrations may result. An even worse case occurs if one of the resonant modes of the cavity in which the shedding structure is located is equal to the vortex shedding frequency and the structural vibration frequency.

Another source of fluid-induced vibration is a turbulent flow field. For an unsteady flow the turbulent fluid fluctuations are transmitted to the structure by fluctuating pressures on the surface of the structure and these pressure fluctuations can produce significant structural vibrations.

The amplitude of resonant and nonresonant components of vibration due to turbulence increases with the amplitude of the force of the flow on the structure and decreases with increasing stiffness of the structure. Methods 
which are in general applicable to reduce the vibrations excited by turbulent flow can be listed as follows:

1. Change the structural shape to reduce the aerodynamic loads

2. Increase the stiffness of the structure

3. Increase the mass ratio

4. Increase the damping. This chiefly affects the resonant vibrations of the structure and can be achieved by incorporating energy-absorbing materials or by permitting local scraping to absorb energy.

A summary of some of the literature on flow-induced vibration has been presented in Ref. 1, while the basic concepts of flow-induced vibrations and the fluid-forcing functions have been discussed in a recent article by M. W. Wambsganss, Ref. 2 .

In the GCFR, the following areas and components deserve attention as far as flow-induced vibrations are concerned: main loop isolation valves, fuel and blanket assembly locking mechanisms, fuel assembly inlet nozzle, fuel assembly exit nozzle, steam generators, circulators, thermal barrier cover plates, flow guides, and protruding components in the primary coolant 1oop.

\subsection{ACOUSTICALLY INDUCED VIBRATIONS}

Acoustically induced vibrations can be defined as vibrations induced by acoustic pressure waves generated by a noise source in the reactor, by a high-speed or unsteady gas flow, or by interaction of gas flows and solid objects. These pressure waves propagate in the primary coolant with the speed of sound. The dynamic stresses in the structure depend on both the root mean square (rms) sound pressure as well as the frequency distribution of the sound field. Acoustics deals with low-level, dynamically excited waves in the structures which are strong enough to cause unacceptable vibrations. 
In the steady state the sound field in the reactor builds up to such a level that the acoustic power emitted by the acoustic sources in the system equals the power dissipated in the primary coolant itself as well as in the structures by compressional waves, shear waves, flexural waves, or torsional waves. The response of the structure to the noise field in a reactor cavity is determined by the power transmission between the acoustic modes of the cavity and the structural modes of the structure. Both the acoustic power generation in the system as well as the coupling between the acoustic field and the structure depend on the physical properties of the primary coolant. The structural response per unit of sound pressure a1so depends on the frequency match.

To assess the acoustically induced stresses in a reactor system it is necessary to estimate, calculate, or measure the sound pressure level spectra in the system.

If measurements are not feasible one has to determine first, the acoustic source strength of the various sources, and second, the distribution of the sound power over the system. Without experimental measurements, preferably on full-scale models or power stations of simflar design, it is difficult to determine the distribution of acoustic energy over a system.

The mean square stress can be determined analytically from the sound pressure spectra but the relation between the mean square stress and failure is hard to predict.

The most important acoustic sources of the $300 \mathrm{MW}(\mathrm{e})$ GCFR are the gas circulators. At General Atomic Company (GA) special efforts are made to develop circulators with a low acoustic source strength and the sound power spectra of these sources are well defined. 


\section{OVERVIEW OF REPORTED PROBLEMS}

According to the Listing of Power Reactors 1976 (Ref. 3), there are 27 gas-cooled, graphite-moderated reactors, of which 14 are in the United Kingdom, 8 in France, 2 in the United States, and 1 each in Japan, Italy, and Spain. Only the 2 U.S. reactors use He as primary coolant while all others use $\mathrm{CO}_{2}$ or air. In Germany He is used as a primary coolant for the experimental $15 \mathrm{MW}(e)$ Julich pebble bed power station, which has been oper-

ating since 1967. A $300 \mathrm{MW}(\mathrm{e})$ helium-cooled pebble bed reactor, the Uentrop thorium high temperature reactor, is presently under construction.

In this summary overview a list of problems encountered in the past will be presented, together with an explanation of the reasons for these problems and the proposed solutions. All information was taken from open literature and the relevant references will be given.

\subsection{EXPERIENCE IN THE UNITED KINGDOM}

There are presently 11 gas-cooled reactors of the MAGNOX (or Mark I type) and 3 advanced gas-cooled (AGR) reactors (or Mark 2 type) operating in the U.K., all of which use $\mathrm{CO}_{2}$ as primary coolant. Table 1 lists these reactors and some of their operating conditions.

At the start of the MAGNOX station programs little attention was paid to flow- and acoustically induced vibrations (Ref. 4). The design of the boiler tube systems was checked theoretically at a late stage for flow-induced vibrations, but the significance of circulator noise was not fully appreciated until, in August 1963, severe damage occurred at the Hinkley Point A Station (Ref. 5). The very detailed analysis of this failure reported in Ref. 5 (see Fig. 1 for plant layout) has shown that most probably the high frequency acoustic aerodynamic exciting force was generated by the aerodynamic interaction between 


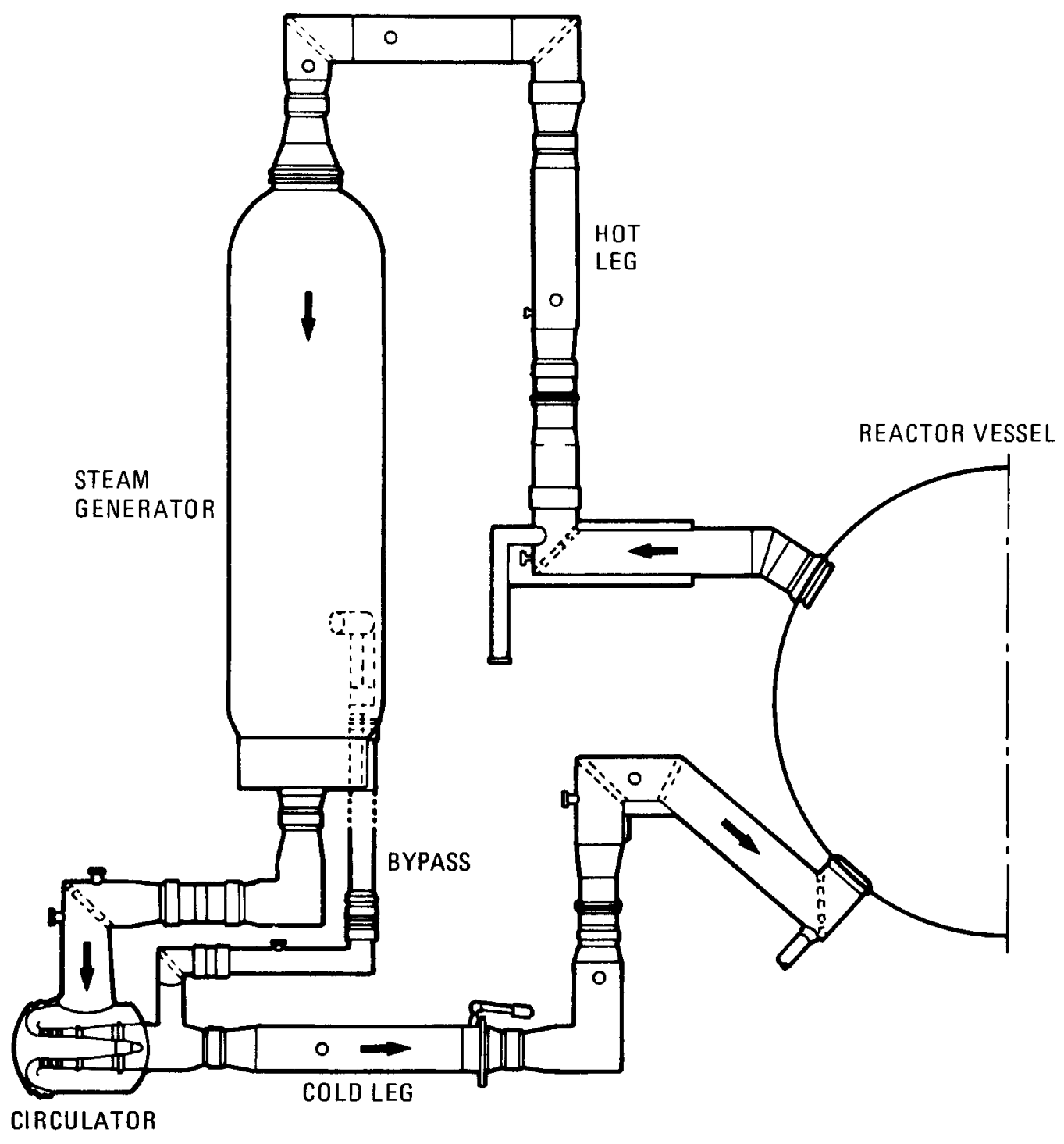

Fig. 1. Hinkley Point A Station - arrangement of gas circuit and components 
TABLE 1

REACTOR CHARACTERISTICS - UNITED KINGDOM

\begin{tabular}{|c|c|c|c|c|c|c|c|c|}
\hline Name of Plant & Type & $\begin{array}{l}\text { Output, } \\
\text { MW(e) } \\
\text { gross/net }\end{array}$ & $\begin{array}{c}\text { Therma1 } \\
\text { Power, } \\
\text { MW }(t)\end{array}$ & $\begin{array}{c}\text { Date of } \\
\text { Regular } \\
\text { Power } \\
\text { Operation }\end{array}$ & Coolant & $\begin{array}{c}\text { System } \\
\text { Pressure, } \\
10^{5} \mathrm{~Pa}\end{array}$ & $\begin{array}{c}\text { Inlet/Outlet } \\
\text { Temperature, } \\
{ }^{\circ} \mathrm{C}\end{array}$ & $\begin{array}{c}\text { Number of } \\
\text { Loops/Circ. }\end{array}$ \\
\hline Calder $\mathrm{Hall}$ & MAGNOX 4 & $240 / 198$ & 1,072 & $8 / 56$ & $\mathrm{CO}_{2}$ & 8 & $150 / 345$ & $4 / 4$ \\
\hline Chapel Cross & MAGNOX 4 & $240 / 200$ & 1,050 & $3 / 59$ & $\mathrm{CO}_{2}$ & 7 & $150 / 345$ & $4 / 4$ \\
\hline Berkeley & MAGNOX 2 & $325 / 275$ & 1,120 & $11 / 62$ & $\mathrm{CO}_{2}$ & 9.8 & $160 / 345$ & $8 / 8$ \\
\hline Bradwell & MAGNOX 2 & $347 / 324.6$ & 1,062 & $11 / 62$ & $\mathrm{CO}_{2}$ & 10.3 & $180 / 390$ & $6 / 6$ \\
\hline Windscale & AGR 1 & $40 / 32$ & 127 & $2 / 63$ & $\mathrm{CO}_{2}$ & 20 & $260 / 460$ & $4 / 4$ \\
\hline Hunterston $A$ & MAGNOX 2 & $400 / 343$ & & $7 / 64$ & $\mathrm{CO}_{2}$ & 10.6 & $205 / 396$ & $8 / 8$ \\
\hline Trawsfynnyd & MAGNOX 2 & $580 / 504$ & 1,720 & $3 / 65$ & $\mathrm{CO}_{2}$ & 17.9 & $202 / 390$ & $6 / 6$ \\
\hline Dungeness A & MAGNOX 2 & $570 / 551$ & 1,680 & $1 / 66$ & $\mathrm{CO}_{2}$ & 19.9 & $245 / 410$ & $4 / 4$ \\
\hline Sizewe11 A & MAGNOX 2 & $500 / 420$ & 1,620 & $12 / 66$ & $\mathrm{CO}_{2}$ & 19.6 & $214 / 410$ & $4 / 4$ \\
\hline Hinkley Point A & MAGNOX 2 & 531 & -- & $5 / 65$ & $\mathrm{CO}_{2}$ & 14.1 & $179 / 373$ & $6 / 6$ \\
\hline Oldbury & MAGNOX 2 & $547 / 530$ & 1,820 & $4 / 68$ & $\mathrm{CO}_{2}$ & 24.6 & $250 / 412$ & $4 / 4$ \\
\hline Wylfa & MAGNOX 2 & $1,000 / 850$ & 3,400 & $7 / 71$ & $\mathrm{CO}_{2}$ & 28.1 & $247 / 414$ & $4 / 4$ \\
\hline Hinkley Point B & AGR 2 & $1,330 / 1,242$ & 2,988 & $10 / 76$ & $\mathrm{CO}_{2}$ & 42.4 & $292 / 634$ & $4 / 8$ \\
\hline Hunterston B & AGR 2 & $1,330 / 1,242$ & 2,988 & & $\mathrm{CO}_{2}$ & 42.4 & $318 / 648$ & $4 / 8$ \\
\hline
\end{tabular}


the inlet guide vanes and the rotating blades of the circulators. Sound pressure levels of $\sim 170 \mathrm{~dB}$ (lin), re $2.10^{-5} \mathrm{~Pa}^{*}$ caused damage to steel structures of up to $8 \times 10^{-3} \mathrm{~m}$ thick. Large sections of the circulator diffuser casings had broken away and caused damage to the circulator blading. Damage was found in all six circuits and extensive fatigue cracking had occurred as a result of this acoustic excitation. The removal of the inlet guide vanes resulted in the largest improvement of all the measures taken and greatly reduced the powerful harmonics previously measured. The inlet flow distribution was further improved by the adoption of inlet vanes and an "egg box" flow straightener. The major components involved in the failure, such as the diffuser and corner cascades, were replaced by new units of a modified design.

One intriguing fact should be mentioned at this point: A number of $\mathrm{CO}_{2}$ circulators of the same design, working at the same operating conditions, have been used and are still in use in the U.K. Only the Hinkley Point A circulators failed in the way described in Ref. 5. The experience with the Hinkley Point A Station showed for the first time that acoustically induced and flow-induced vibrations form important aspects of GCR design.

During the commissioning of the Dungeness A Station another flowinduced phenomenon was noticed. Large dynamic stresses were found to be occurring in some of the tubes of the superheater due to flow-induced vibrations of the tubes, amplified by cavity resonance within the boiler shell (Refs. 6 and 7). The pitching of the tubes precluded baffling to increase the resonant frequency of the cavities and model tests in a wind tunnel had to be used to determine the cause and find a cure.

Another vibration problem in the Dungeness A Station reported in Ref. 7 deserves attention because it is a typical example of what happens if the frequency of a periodic disturbance in the gas flow coincides with one of the natural frequencies of a duct or cavity. During commissioning tests it

*For acoustic terms and units see Appendix A. 
was observed that excessive vibration of the ducting of the reactor bypass circuit occurred when the gas circulator was operating within a particular range of speeds (See Fig. 2 for the gas circuit layout and the bellows-unit). The bypass circuit was instrumented with strain gauges, accelerometers, and pressure transducers, and tests were carried out first using air at room temperature and second, carbon dioxide at $250^{\circ} \mathrm{C}$. During both tests the gas density was increased in increments up to the normal operating value. Analysis of the results obtained from these tests indicated that the cause of the severe vibration of the ducting was the coincidence in frequency of a periodic disturbance in the gas flow and the aerial vibration in the duct. Because it was impracticable to change the response of the ducting, the source of the gas instability had to be determined and eliminated.

Further investigations showed that the pronounced vibration of the bypass duct was initiated by the generation of vortices at the trailing edges of the two cruciforms, connected together along the axis of the bellows by a flat plate, providing internal support for the bellows. The shape of the trailing edges was modified by the addition of fairings $(0.25 \mathrm{~m}$ long with an included angle of $14 \mathrm{deg}$ ), which eliminated the vibration of the ducting. The experience with the Dungeness A reactor showed that with complex structures there is difficulty in determining the parameters associated with flow-induced vibration from basic data.

Damage occurred to the insulation of a circulator bowl of another MAGNOX station in Anglesey, the Wylfa Station, due to flow-induced vibration as a result of vortex shedding from the inlet spokes of the circulator under reverse flow conditions. This occurred when one circulator was shut down while another was running (Ref.6).

On the basis of the experience with the Mark I stations and a 30 MW(e) AGR demonstration plant in Windscale, the new $1240 \mathrm{MW}(e)$ net AGR stations were committed to construction. Little or no subcomponent testing had been done on the main components of the plants and problems arose. As pointed out by Vaughan in Ref. 4, "the technical problems and the solutions found for them were not in themselves expensive but it was the fact that they 

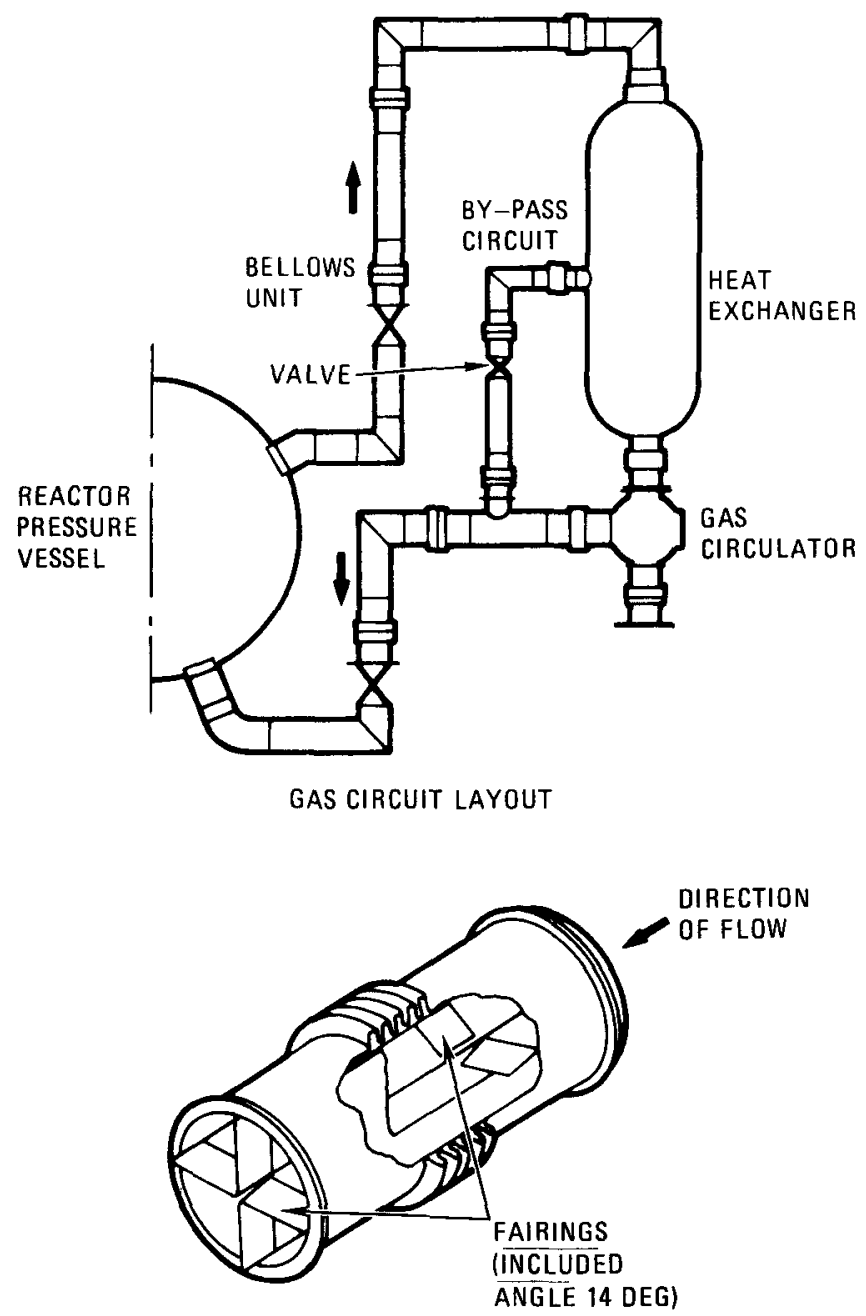

BELLOWS UNIT SHOWING MODIFICATIONS

TO CRUCIFORM TRAILING EDGES

Fig. 2. Dungeness A MAGNOX station 
caused delays to completion which was mainly responsible for the large extra costs incurred." The first single cavity AGR, Hinkley Point B, is now operating at its interim power level of $500 \mathrm{MW}(\mathrm{e})$, after losing two years due to vibration problems. Early 1975 mechanical failures were experienced in five fuel channel orifices (Ref. 4). These continuously variable orifices serve to control the channel gas flow. Examination showed that structural failures had occurred, with one extreme case where the fuel assembly had split into two separate parts. It appeared that the center body of the orifice and its supporting drive shaft had vibrated violently and had triggered a rapidly divergent vibration mechanism, leading to failure of several components.

The original orifice design was based on the assumption that the loading on the orifice was sufficient to ensure continuous mechanical contact between the orifice center body and its housing, with very little relative movement. Development tests had shown some orifice movement near the two ends of travel, leaving what was believed to be an acceptable operating range in between. What was not fully appreciated was the sensitivity of the bias load to very small changes in certain dimensions and how near to a runaway situation the original design was. By drilling holes along the fins of the orifices and by introducing higher stabilizing loads, this vibration problem was solved.

Besides these orifice vibration problems, difficulties were encountered with the Hinkley Point B circulators. According to Ref. 4 three vibration problems had to be solved. In the first place severe vibrations of the circulator shaft were observed after shutdown of the reactor for short periods of time. Thermal gradients in the shaft caused distortions which resulted in excessive vibrations during startup. This problem was solved by closing the isolating domes after shutdown. In the second place high circulator shaft vibrations were generated by aerodynamic effects on the inlet guide vanes for angles smaller than 17 deg. These motor-operated inlet guide vanes serve as flow control devices. Efforts to modify the inlet guide vanes and the installation of flow straighteners to stabilize the flow at the entrance to the circulator throat proved to be insufficient to solve 
the vibration problem for all circulators. A minimum vane position of 17 deg has now been specified and no vibrations have since been observed. The third and last vibration problem was a mechanical problem related to the flange mounting of the horizontal circulators. This was solved by redesign.

As mentioned before, two years were lost to solve the difficulties associated with the circulators and the coolant-gas flow-control valves. This delay was the more disappointing because these components had been subjected to rig tests and the failures showed up only in the final engineering tests prior to operation. Extra time was lost because the problems were solved sequentially and not in parallel. It was found that many of the problems occur only when several machines are run in parallel.

It should be noted that the first two twin advanced gas-cooled reactors are now operating and that three others, i.e., Hartlepool, Heysham, and Dungeness, will follow two to three years later. The orders for these three follow-up units were taken by three design and construction companies, and the designs were different in many respects. Therefore the solutions found on one design were not always of great relevance to the other reactors. In particular, it is interesting to note that Hinkley Point, Hunterston, and Dungeness B designs all have single cavity pressure vessels, while the Hartlepool and Heysham designs have podded vessels. The circulators for all but the Dungeness B AGRs are fully encapsulated; that is, they operate entirely within the pressure circuit but all moving parts may be removed from the reactor and replaced on a routine basis. For the Hinkley Point design the circulator is placed horizontally below the steam generators, there being two circulators to each of three steam generators to reduce size and give diversity in operation. According to Ref. 4, this proved to be a very doubtful advantage. In the Hartlepool design there are 8 circulators operating vertically, one below each steam generator pod.

Consequently the experience gained with one design is not relevant or applicable for the other, modified designs, and new problems can be expected. 
The operating experience with the only $\mathrm{CO}_{2}$-cooled Japanese MAGNOX reactor, to be discussed later, is an excellent example of the disadvantages of this approach.

\subsection{EXPERIENCE IN JAPAN}

The only gas-cooled power reactor in Japan, the $160 \mathrm{MW}(\mathrm{e})$ MAGNOX, single cavity, $\mathrm{CO}_{2}$-cooled Tokai Japco plant reached criticality in early 1965 and started power generation in November 1965. During the first 3-1/2 years of commercial operation, flow-induced and acoustically induced vibration failures caused 400 days of plant shutdown; thus, roughly $30 \%$ of the available operating days were lost. The following problems were encountered and subsequently solved satisfactorily (Ref. 8). (See Fig. 3 for layout of IMAI power station.)

\subsubsection{Fatigue Failure of Tubes of Low Pressure Superheater Tube Bends Due to Vortex Shedding}

An improvement of the damping coefficient or loss factor by a factor of 10 was achieved in a rather unconventional way by inserting power transmission chains through the spaces between staggered tubes from the top to the bottom of the tube banks and by putting a 10-kg weight at the bottom end of the chains. For those spaces where insertion of the chains was impossible, thin stainless steel strips were mounted giving a comparable damping effect. This solution solved these vibration problems.

\subsubsection{Fracture of Splitter Plates and Fixing Bolts at Main Blower Outlet Bends}

Examination showed that the very turbulent flow around the splitter caused buffeting on the damaged components. Modification of the circulator outlet bend splitter solved this problem.

\subsubsection{Failure of Gas Circulator Inlet Bellows}

Fatigue fracture due to vibration appeared to be the cause of the damage in this case. High velocity gas $(v>65 \mathrm{~m} / \mathrm{sec})$ created a very 


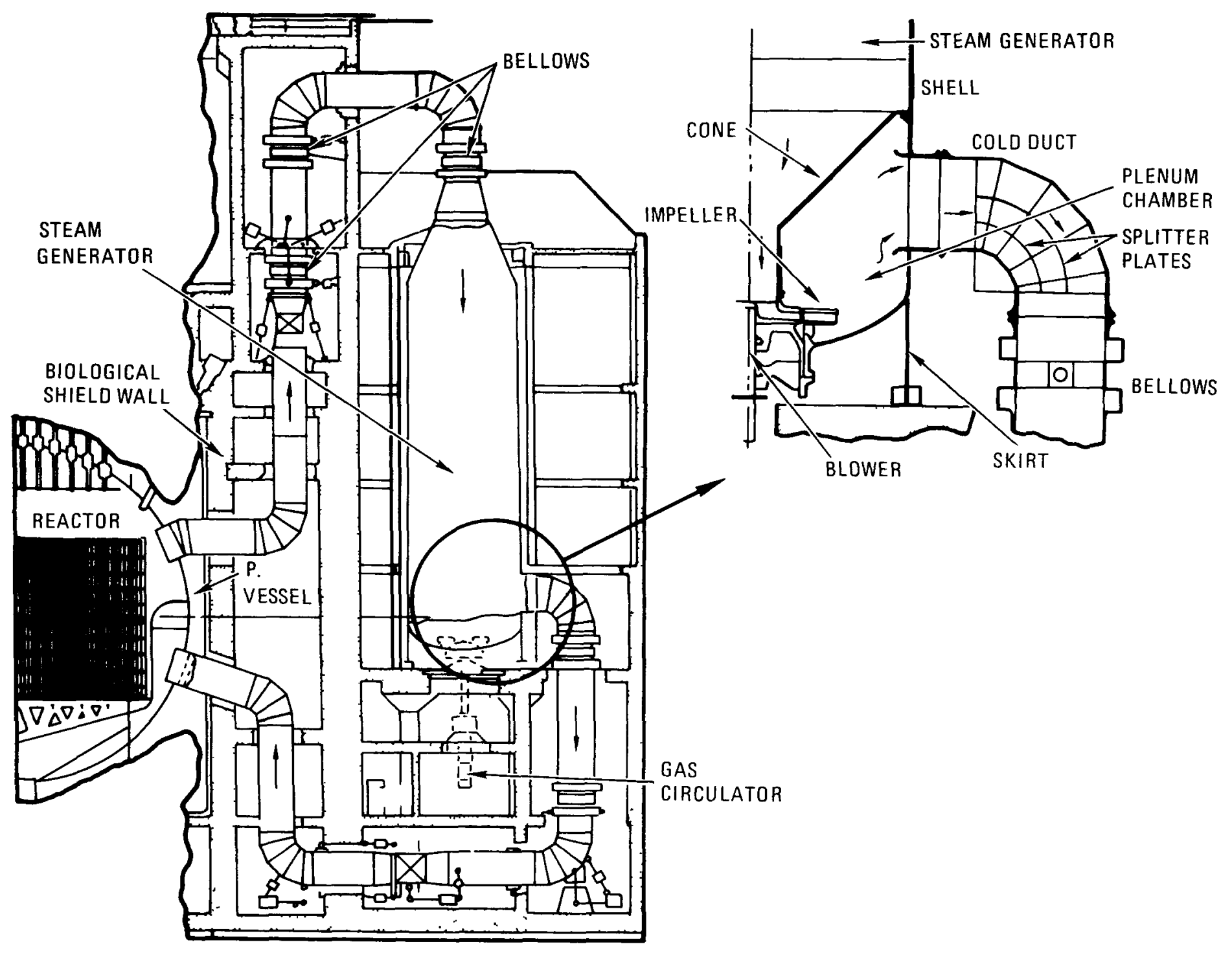

Fig. 3. IMAI Station - arrangement of gas circuit and components 
turbulent flow region in the inlet section of the bellows mounted between the conical inlet section and the circulator. The rigidity of the material in this section was judged insufficient to be used in this region and a solution was found by increasing the plate thickness of the internal sleeves from $2.7 \times 10^{-3} \mathrm{~m}$ to $9.6 \times 10^{-3} \mathrm{~m}$ and by fixing the top of the sleeves.

\subsubsection{Breakaway of Insulation Cover Plates at Nozzles of Hot Gas Outlet Ducts}

The cause of this failure was fatigue. The missing cover plates and thermal isolation material were replaced although with significant difficulty due to the radiation levels. The new cover plates were welded to the insulation cover plates of the hot ducts.

It is interesting to note that:

1. The failures occurred in all four circuits.

2. The circulator layout of this MAGNOX station is different from those in the U.K. especially as regards the circulator location and adjacent ducting. Hence the U.K. experience could not be turned to account (see Figs. 1 and 3 ).

3. The one-cavity MAGNOX reactor was equipped with vibration detection instruments in the steam generator unit and near the thrust bearing of the gas circulators, and noise detection was provided near the gas circulator outlet region. Thanks to this noise and vibration equipment and operator surveillance, shutdown of the plant was possible before damage was done to the system.

4. Notwithstanding the fact that for the single-cavity MAGNOX station the gas ducts are not completely surrounded by concrete, it nevertheless proved to be difficult to repair damaged primary circuit components, particularly because of the radiation levels. 
5. In comparison with the early U.K. reactors this Japanese MAGNOX station has twice as high a system pressure (see Table 2).

The experience in Japan can be summarized as follows:

1. Custom-designed reactors will have special problems which cannot be accurately predicted on the basis of experience with other reactors of the same type. Especially if the mass flow and the system pressure vary significantly, extrapolation or interpolation is difficult.

2. Noise- and vibration-measuring equipment can be valuable.

3. If a flow-induced or acoustically induced vibration failure of the thermal barrier cover plates occurs, it is difficult to repair.

\subsection{EXPERIENCE IN FRANCE}

In France 9 gas-cooled reactors have been constructed. One of these, the $3 \mathrm{MW}(\mathrm{e})$ net Marcoule G1 reactor, decommissioned for economic reasons, was air cooled, while all others, ranging in size from $40 \mathrm{MW}(\mathrm{e})$ to $560 \mathrm{MW}(\mathrm{e})$, use $\mathrm{CO}_{2}$ as primary coolant. Table 3 lists some of the reactor characteristics. In studying this table it is interesting to note the gradual increase in thermal power in the Chinon series and the standardization of the Chinon 3 design for all follow-up units. Also the power station in Vandellos in Spain has more or less the same characteristics as Chinon 3 (see Table 2). Consequently most of the experience obtained with Chinon 3 was directly applicable to the follow-up units. Except for Chinon 1 and 2, which have steel vessels, all other reactors are of the PCRV type although for Chinon 3 only the core was encapsulated while the steam generators were located outside the PCRV in steel vessels. The St. Laurent 1 reactor was 
TABLE 2

REACTOR CHARACTERISTICS - JAPAN, ITALY, SPAIN

\begin{tabular}{|c|c|c|c|c|c|c|c|c|}
\hline Name of Plant & Type & $\begin{array}{l}\text { Output, } \\
\text { MW(e) } \\
\text { gross/net }\end{array}$ & $\begin{array}{c}\text { Thermal } \\
\text { Power, } \\
\text { MW }(t)\end{array}$ & $\begin{array}{c}\text { Date of } \\
\text { Regular } \\
\text { Power } \\
\text { Operation }\end{array}$ & Coolant & $\begin{array}{c}\text { System } \\
\text { Pressure, } \\
10^{5} \mathrm{~Pa}\end{array}$ & $\begin{array}{c}\text { Inlet/Outlet } \\
\text { Temperature, } \\
{ }^{\circ} \mathrm{C}\end{array}$ & $\begin{array}{l}\text { Number of } \\
\text { Loops/Circ. }\end{array}$ \\
\hline $\begin{array}{c}\text { Tokai Japco, } \\
\text { Japan }\end{array}$ & MAGNOX 1 & $166 / 157$ & 587 & $7 / 66$ & $\mathrm{CO}_{2}$ & $15.4 / 14.7$ & $207 / 386$ & $4 / 4$ \\
\hline Latina, Italy & MAGNOX 1 & $210 / 220$ & 705 & $1 / 64$ & $\mathrm{CO}_{2}$ & 13.7 & $180 / 390$ & $6 / 6$ \\
\hline Vandellos, Spain & Gas/Graph & $503 / 486$ & 1,750 & $5 / 72$ & $\mathrm{CO}_{2}$ & 29 & $225 / 400$ & $4 / 4$ \\
\hline
\end{tabular}


TABLE 3

REACTOR CHARACTERISTICS - FRANCE

\begin{tabular}{|c|c|c|c|c|c|c|c|c|}
\hline Name of Plant & Type & $\begin{array}{l}\text { Output, } \\
\text { MW(e) } \\
\text { gross/net }\end{array}$ & $\begin{array}{l}\text { Thermal } \\
\text { Power, } \\
\text { MW }(t)\end{array}$ & \begin{tabular}{|c|} 
Date of \\
Regular \\
Power \\
Operation
\end{tabular} & Coolant & $\begin{array}{c}\text { System } \\
\text { Pressure, } \\
10^{5} \mathrm{~Pa}\end{array}$ & $\begin{array}{c}\text { Inlet/Outlet } \\
\text { Temperature, } \\
{ }^{\circ} \mathrm{C}\end{array}$ & $\begin{array}{l}\text { Number of } \\
\text { Loops/Circ. }\end{array}$ \\
\hline Marcoule G1 & Air/Graph & 3 & & $5 / 56$ & Air & 1 & $18 / 165$ & $1 /--$ \\
\hline $\begin{array}{l}\text { Marcoule G2, } \\
\quad \text { Marcoule G3 }\end{array}$ & Gas/Graph & $2 \times 40 / 36$ & $2 \times 260$ & $\begin{array}{l}4 / 59 \\
5 / 60\end{array}$ & $\mathrm{CO}_{2}$ & 15 & $140 / 365$ & $1 / 2$ \\
\hline Chinon 1 & Gas/Graph & $80 / 70$ & 300 & $2 / 64$ & $\mathrm{CO}_{2}$ & 29 & $145 / 355$ & $1 /--$ \\
\hline Chinon 2 & Gas/Graph & $240 / 210$ & 800 & $2 / 65$ & $\mathrm{CO}_{2}$ & 25 & $195 / 365$ & $4 / 4$ \\
\hline Chinon 3 & Gas/Graph & $500 / 480$ & 1,560 & $8 / 67$ & $\mathrm{CO}_{2}$ & 26.5 & $240 / 410$ & $4 / 4$ \\
\hline St. Laurent 1 & Gas/Graph & $500 / 487$ & 1,652 & $3 / 69$ & $\mathrm{CO}_{2}$ & 26.5 & $225 / 400$ & $4 / 4$ \\
\hline St. Laurent 2 & Gas/Graph & $530 / 515$ & 1,691 & $8 / 71$ & $\mathrm{CO}_{2}$ & 28.5 & $235 / 410$ & $4 / 4$ \\
\hline Bugey 1 & Gas/Graph & $560 / 540$ & 1,954 & $-/ 72$ & $\mathrm{CO}_{2}$ & 43.1 & $217 / 402$ & $4 / 4$ \\
\hline
\end{tabular}


the first reactor with an integrated PCRV. Notwithstanding a certain degree of standardization reached, all plants were regarded as prototypes.

As regards flow-induced and acoustically induced vibration failures the following has been reported (Ref. 9):

1. Gas flow-induced vibrations led to fatigue failures of casing sections (Chinon 1, Chinon 3, and St. Laurent 1), to cracking of guide vanes (Chinon 2 and 3 ), and cracking of the circuit itself (Chinon 3, Marcoule G3). Chinon 3 was shut down in 1974 to rebuild the entire $\mathrm{CO}_{2}$ ducting while the same repairs were made for Marcoule G3 at the end of 1973.

2. Pressure fluctuations caused by vortex shedding in the heat exchanger banks of Chinon 3, amplified by the acoustic resonances of the primary coolant system caused vibrations and severe stresses in the structure. The reactor had to be derated while a solution was sought. In view of the complex heat exchanger circuit, redesign of the shedding components was not feasible and the problem was solved by welding tuning volumes on every boiler to change the resonance frequencies of the cavities. This solution was possible because the steam generator units were located outside the PCRV in steel pressure vessels.

\subsection{EXPERIENCE IN THE UNITED STATES}

Two gas-cooled power reactors have been constructed in the U.S.: the $40 \mathrm{MW}(\mathrm{e})$ net Peach Bottom 1 prototype reactor for Philadelphia Electric and the $330 \mathrm{MW}(\mathrm{e})$ Fort St. Vrain reactor for the Public Service Company of Colorado. Both reactors use He as primary coolant (see Table 4). The Peach Bottom plant reached criticality on March 3, 1966, and was shut down, for economic reasons, after 1349 effective full power days, having generated $1.2 \times 10^{6} \mathrm{MW}(\mathrm{e}) \mathrm{hr}$ net, on October 31 , 1974. Motor-driven centrifugal 
TABLE 4

REACTOR CHARACTERISTICS - UNITED STATES

\begin{tabular}{l|c|c|c|c|c|c|c|c}
\hline & Name of Plant & $\begin{array}{c}\text { Output, } \\
\text { MW(e) } \\
\text { gross/net }\end{array}$ & $\begin{array}{c}\text { Thermal } \\
\text { Power, } \\
\text { MW }(t)\end{array}$ & $\begin{array}{c}\text { Date of } \\
\text { Regular } \\
\text { Power } \\
\text { Operation }\end{array}$ & Coolant & $\begin{array}{c}\text { System } \\
\text { Pressure, } \\
10^{5} \text { Pa }\end{array}$ & $\begin{array}{c}\text { Inlet/Outlet } \\
\text { Temperature, } \\
{ }^{\circ} \mathrm{C}\end{array}$ & $\begin{array}{c}\text { Number of } \\
\text { Loops/Circ. }\end{array}$ \\
\hline Peach Bottom & HTGR & $42 / 40$ & 115 & $5 / 67$ & He & 23.6 & $344 / 728$ & $2 / 2$ \\
Fort St. Vrain & HTGR & $342 / 330$ & 842 & -- & He & 49.3 & $400 / 785$ & $2 / 4$ \\
\hline
\end{tabular}


1.5 MW/3500 rpm circulators were used to pump the primary coolant (maximum temperature $712^{\circ} \mathrm{C}$ ) through the system. During preoperational testing with He under full pressure but partial temperature conditions, vibration measurements were made at various locations in the primary coolant system, such as in the steam generator vessels and in the core cavity. The results of these tests indicated that the dynamic loads did not surpass the design limits and that therefore no problems were to be expected. The successful commercial operation of the Peach Bottom reactor proved, in fact, that the flow-induced and acoustically induced dynamic loads were smaller than the anticipated design loads.

Fort St. Vrain (FSV), the first nuclear reactor system in the U.S. with a prestressed concrete reactor vessel, is presently in the power ascension phase. Until now 27\% reactor power has been reached (which means $239 \%$ of the maximum He flow, 40.7 bar He pressure and a maximum He temperature of $532^{\circ} \mathrm{C}$ ). Both during the preoperational hot flow tests (Ref. 10) as well as during the initial startup testing no acoustically induced or flow-induced vibrations have been observed.

\subsection{EXPERIENCE IN ITALY}

One gas-cooled reactor of the MAGNOX 1 type has been constructed in Latina in Italy and started regular power operation in January 1964 . This 6-loop $\mathrm{CO}_{2}$-cooled station, comparable in size with the Tokai Japco plant in Japan (see Table 2), experienced vibration problems due to resonance of the guide vanes, acoustic resonances in the bypass gas circuit, and tube resonances in the boilers. Details on these difficulties have not been published to this author's knowledge. 


\subsection{EXPERIENCE IN GERMANY}

The design of the $15 \mathrm{MW}(\mathrm{e})$ experimental pebble bed reactor in Julich, Germany is quite different from that of the MAGNOX reactors, AGRs, and HTGRs discussed above. The main difference is the type of fuel element. Instead of rod- or block-type fuel elements, spheres or pebbles $6 \times 10^{-2} \mathrm{~m}$ in diameter are used. The total number of pebbles in the reactor is approximately 100,000. During operation the pebbles are continuously withdrawn at the bottom and reinjected at the top of the pebble bed, while spent pebbles are continuously replaced by new ones. The primary coolant is forced upward through the bed by two electric-driven circulators. Insofar as can be determined from a search of the literature no flow-induced or acoustically induced vibration failures have been encountered with this reactor. 
4. RELEVANCE OF THE EXPERIENCE FOR THE GCFR PROJECT

The failures experienced and the investigations carried out have clearly shown the importance of acoustically induced and flow-induced vibration phenomena for gas-cooled reactors and thus for the gas-cooled fast breeder reactor. The results can be summarized as follows.

1. Failure-prone components are: the circulators and adjacent ducting, the steam generators, the thermal barrier cover plates, orifice valves, and flow straighteners.

2. An increase in mass flow and gas density implies higher dynamic loads and hence a higher probability for flow-induced vibrations.

3. The higher the horsepower rating of the primary coolant circulators, the higher the acoustic source strength, and consequently the higher the dynamic loads on the structures.

4. Although extensive component and subcomponent tests are of great value for the development of the components themselves, they have in general, for $\mathrm{CO}_{2}$ reactors at least, limited value for the prediction of the behavior of the plant as a whole unless excess conservatism can be tolerated in the design. It proved to be difficult and expensive to simulate the reactor operating conditions in test rigs.

5. Some kind of endurance testing appears to be advisable.

6. A11 flow-induced and acoustically induced vibration problems encountered in the past have been solved satisfactorily 
a1though of ten at high costs due primarily to the long construction delays. Careful analysis beforehand and excess conservatism are apparently of paramount importance for success.

7. The closer the resemblance between the $300 \mathrm{MW}(\mathrm{e})$ demonstration plant and the commercial follow-up units, the fewer the chances of failures for the larger plants.

8. It is necessary to develop diagnostic tools which can be inserted in the reactor to measure, among other parameters, the sound pressure levels.

9. It appears advisable that all components essential for safe and reliable operation of the plant and vulnerable to flowinduced or acoustically induced vibrations be made capable of repair or replacement.

10. An encouraging result is that He seems to be a somewhat better coolant than $\mathrm{CO}_{2}$ as far as flow-induced or acoustically induced vibrations are concerned. A detailed theoretical analysis of the vibration response of reactor components in $\mathrm{He}, \mathrm{CO}_{2}$, and air (Ref. 11) has shown that differences arise in the acoustic power generation, in the transmission of acoustic energy through the system, and in the response of the structures to the acoustic fields. The main conclusion arrived at is that "the acoustic characteristics of He and $\mathrm{CO}_{2}$ systems are very different and the net result in terms of the dynamic stress in each component is difficult to predict. However, on the average, the problem of acoustically induced stress is less severe in He than in $\mathrm{CO}_{2} .^{\prime \prime}$ (Appendix $\mathrm{B}$ provides more background information on the difference between He and $\mathrm{CO}_{2}{ }^{\circ}$ ) It must be stressed that this conclusion depends heavily on the operating characteristics of the system. It is, for example, not sufficient to consider a particular circulator running at the same speed in each gas. The design and 
operating conditions of the circulator are determined by the required mass flows per loop. Comparison of the circulator operating conditions of the Fort St. Vrain reactor and those of the GCFR shows that the mass flow of the breeder is twice as high as that of FSV, the inlet pressure is 1.84 times higher, the gas density is 1.53 times higher, the pressure rise of the circulator is approximately 3 times higher, and consequently 4 times as much shaft power is required for each of the breeder circulators relative to a Fort St. Vrain circulator. Using the Peistrup-Wesler (Ref. B-2) correlation (after correction for He) to estimate the acoustic source strength of the FSV and GCFR circulators one finds:

$$
\mathrm{L}_{\mathrm{P}, \mathrm{FSV}}=137 \mathrm{~dB}\left(\mathrm{re} 10^{-12} \mathrm{~W}\right)
$$

or

$$
\mathrm{W}_{\mathrm{FSV}}=50 \mathrm{~W}
$$

and

$$
\mathrm{L}_{\mathrm{P}, \mathrm{GCFR}}=146 \mathrm{~dB}\left(\text { re } 10^{-12} \mathrm{~W}\right)
$$

or

$$
\mathrm{W}_{\mathrm{GCFR}}=426 \mathrm{~W} \text {. }
$$

Therefore, the acoustic energy emitted from a 300 MW(e) GCFR circulator is more than eight times that emitted from an FSV circulator. Although lower overall acoustic sound power levels are expected for both reactors, thanks to the special efforts made by General Atomic to develop circulators with a low acoustic source strength, these figures nevertheless give an idea of the increase in the sound pressure levels that can be expected in the GCFR. Another reason why higher dynamic loads must be anticipated for the breeder reactor results from the fact that the total primary coolant pressure boundary area is smaller than that of the FSV reactor although significant absorption can be expected in the GCFR core. 


\section{CONCLUSIONS}

It can be concluded that:

1. Most of the failures occurred in the past because the design of components went ahead before enough was known of the environment in which they had to work, and because flow-induced and acoustically induced dynamic loads were underestimated.

2. A11 problems encountered proved to be solvable although sometimes at high costs.

3. It is prudent to evaluate the GCFR system in detail for potential flow-induced and acoustically induced vibration problems. 
1. Blevins, R. D., "Flow Induced Vibration," General Atomic Report GA-A13380, October 1, 1975.

2. Wambganss, M. W., "Understanding Flow Induced Vibrations Part I: Basic Concepts; F1uid Forcing Functions," Sound and Vibration, November 1976.

3. "Alphabetical Listing of Power Reactors 1976," Nucl. Eng. Int., April Supplement 1976.

4. Vaughan, R. D., "AGR Experience and Its Relevance to Future Gas-Cooled Reactors," 1976 ASME-ANS Internationa1 Conference on Advanced Nuclear Energy Systems, Pittsburgh, Pennsylvania.

5. Rizk, W., and D. F. Seymour, "Investigations Into the Failure of Gas Circulators and Circuit Components at Hinkley Point Nuclear Power Station," Proc. Inst. Mech. Engr. 179, Pt. 1, No. 21, pp. 627-703.

6. Gibbs, K. P., and D. Tattersa11, "The Influence of Operating Experience on British Gas Cooled Reactor Design," ANS Topical Meeting on Gas-Cooled Reactors: HTGR and GCFBR, May 7-10, 1974, Gatlinburg, Tennessee (CONF740501).

7. Derbyshire, J. F., and K. Stead, "Vibration Problems in Nuclear Power Plant," Proc. Inst. Mech. Engr., 1966-1967, 181, Pt. 31, pp. 81-88.

8. Imai, Y., "Main Failures in the Primary Circuit Leading to Plant Power Loss at the Tokai Power Station," Proceedings of a symposium on performance of nuclear power reactor components, I.A.E.A., Prague, 10-14 November 1969.

9. Stolz, J., and B. Boudouresques, "French Gas Cooled Reactor Experience," ANS Topical Meeting on Gas-Cooled Reactors: HTGR and GCFBR, May 7-10 1974, Gatlinburg, Tennessee (CONF-740501).

10. Corea, V. A., "Hot Flow Test Special Data Summary Report PSC," General Atomic unpublished data. 
11. Whitton, P. N., and W. J. Hammill, "Vibration Response of Reactor Components in Helium, Carbon-Dioxide and Air," Paper E5/6, 2nd SMIRT Conference, Berlin, 1973.

12. Peistrup, C. F., and J. E. Wesler, J. Acoustic Soc. America 25, No. 2, 1953. 
APPENDIX A

ACOUSTIC TERMS AND UNITS

Only those terms and units used in this report will be explained in this appendix. For a more elaborate discussion see Ref. A-1.

Sound can be defined as mechanical vibrations in gaseous, fluid, or solid media, which are characterized by their frequency, their amplitude, and their phase. Not all mechanical vibrations can be perceived by the human ear; they must be of a certain magnitude and the frequency must be within certain limits. In a gaseous medium, such as helium, the propagation of mechanical vibrations takes place in the form of density fluctuations in the direction of propagation. The most common way to measure these density fluctuations is to measure the associated variations in pressure, i.e., to measure the root mean square sound pressure in $\mathrm{Pa}$. (Sometimes it might also be desirable to measure the particle velocity of the vibrating gas particles.)

In view of the wide dynamic range of sound pressures which can be perceived by the human ear and the fact that the hearing mechanism responds to changes in sound pressure in a relative manner rather than in an absolute way, it is inconvenient to use sound pressures directly as a measure. Therefore a relative scale of sound pressure, the decibel scale, is used.

The decibel is defined as 10 times the logarithm to the base 10 of the ratio between two quantities of power; hence the sound power level

$$
L_{P}=10 \log _{10} \frac{W}{W_{o}}, d B
$$

where $W=$ sound power in watts, and

$W_{0}=$ reference sound power in watts equal to $10^{-12} \mathrm{~W}$. 
Note that the term level indicates that the given quantity has a certain level above the reference quantity of $10^{-12} \mathrm{~W}$. Therefore $\mathrm{L}_{\mathrm{P}}$ is the sound power level in $\mathrm{dB}$ re $10^{-12} \mathrm{~W}$.

As the sound power is related to the sound pressure squared, the sound pressure level can be defined as

$$
L_{p}=20 \log _{10} \frac{p}{p_{o}}, d B
$$

where $\mathrm{p}=$ sound pressure in $\mathrm{Pa}$, and

$\mathrm{p}_{\mathrm{o}}=$ reference sound pressure equal to $2 \times 10^{-5} \mathrm{~Pa}$.

Hence by using the relationship in Eq. A-1 the sound power in $W$ can be derived from the sound power level $\mathrm{L}_{\mathrm{P}}$ in $\mathrm{dB}$ re $10^{-12} \mathrm{~W}$ and vice versa.

Equation A-2 presents the relationship between the sound pressure in $\mathrm{Pa}$ and the sound pressure level in $\mathrm{dB}$ re $2 \times 10^{-5} \mathrm{~Pa}$. 


\section{REFERENCE}

A-1. Beranek, Leo L., Noise and Vibration Control, McGraw-Hil1, New York, 1971.

A-3 
APPENDIX B

COMPARISON OF THE INFLUENCE OF

CARBON DIOXIDE AND HELIUM GAS PROPERTIES

ON ACOUSTICALLY INDUCED AND FLOW-INDUCED VIBRATION PHENOMENA

Before comparing the relative merits of helium and carbon dioxide as primary coolant from a flow-induced vibration point of view, it is worthwhile to review the thermodynamic properties of these two gases because these properties determine to a great extent the design and operating conditions of a reactor. Parameters like the required mass flow, pressure drop, and pumping power of the circulators depend on both the basic thermodynamic properties and the design of the plant. Table B- 1 summarizes some of the basic properties of $\mathrm{CO}_{2}$ and He for the specified reactor conditions.

It has been shown (Ref. B-1) that if the core inlet and outlet temperatures, the core pressure drop, and the average pressure are the same, the ratio of core pumping power to thermal power is smaller for $\mathrm{CO}_{2}$ than for He and the ratio of the heat transfer area to the flow area is higher for $\mathrm{CO}_{2}$ than for $\mathrm{He}$.

The core thermal power per unit flow area and the core thermal power per unit heat transfer area are smaller for $\mathrm{CO}_{2}$ compared with He. Thus, it can be seen that care must be exercised in comparing $\mathrm{He}$ and $\mathrm{CO}_{2}$ cooled reactors. The gas properties affect the design of the reactor.

\section{Acoustically Induced Vibrations}

Several sources of acoustic disturbances in the flow field of the primary coolant can be identified as, for example, the primary coolant circulators and turbulent shear flow around structures or components such as steam generators and isolation valves. As the sound pressure levels in 
TABLE B-1

BASIC PROPERTIES OF He AND $\mathrm{CO}_{2}$ FOR SPECIFIED REACTOR CONDITIONS

\begin{tabular}{|c|c|c|c|}
\hline & $\begin{array}{c}\text { MAGNOX } \\
\text { Hinkley Point A }\end{array}$ & $\begin{array}{l}\text { HTGR } \\
\text { Fort St. Vrain }\end{array}$ & $\begin{array}{l}\text { GCFR } 300 \text { MW Demo. } \\
\text { Plant Ref. Design }\end{array}$ \\
\hline Primary coolant & $\mathrm{CO}_{2}$ & $\mathrm{He}$ & $\mathrm{He}$ \\
\hline Coolant temperature, core in/core out, $K$ & $452-646$ & $667-1058$ & $595-823$ \\
\hline Coolant pressure, $\mathrm{Pa}$ & $1.31 \times 10^{6}$ & $4.7 \times 10^{6}$ & $9 \times 10^{6}$ \\
\hline Coolant density $\rho, \mathrm{kg} / \mathrm{m}^{3(\mathrm{a})}$ & 14.97 & 3.41 & 6.06 \\
\hline Dynamic viscosity $\mu, \mathrm{Pa} \mathrm{s}^{(\mathrm{a})}$ & $0.017 \times 10^{-3}$ & $0.047 \times 10^{-3}$ & $0.036 \times 10^{-3}$ \\
\hline Kinematic viscosity $\nu, \mathrm{m}^{2} / \mathrm{s}(\mathrm{a})$ & $1.17 \times 10^{-6}$ & $13.51 \times 10^{-6}$ & $6.00 \times 10^{-6}$ \\
\hline Heat conductivity $\mathrm{K}, \mathrm{W} / \mathrm{mK}^{(\mathrm{a})}$ & 0.158 & 0.372 & 0.277 \\
\hline Specific heat ratio $\gamma^{(a)}$ & 1.28 & 1.66 & 1.66 \\
\hline Specific heat at constant pressure, $\mathrm{J} / \mathrm{kg} \mathrm{K}^{(\mathrm{a})}$ & 1025 & 5199 & 5199 \\
\hline Compressibility factor, $\mathrm{L}^{\text {(a) }}$ & 0.99 & 1.02 & 1.02 \\
\hline Velocity of sound $c, m / s(a)$ & 347.5 & 1500 & 1585 \\
\hline Prandt 1 number $(a)$ & 0.72 & 0.68 & 0.67 \\
\hline
\end{tabular}

(a) Average values 
the coolant are primarily due to the circulators, the discussion can be restricted to this noise source only. A short discussion will be given of the influence of the gas properties on noise generation, propagation, and absorption.

There exist two correlations to calculate the acoustic source strength of gas circulators, the Peistrup-Wesler correlation (Ref. B-2) and the C. W. Allen correlation (Ref. B-3). The Pelstrup-Wesler correlation, developed for circulators operating in air at horsepower ratings smaller than 100, gives the overall acoustic source strength as a function of the shaft horsepower HP and the number of rotor blades $\mathrm{N}$ as

$$
\mathrm{PWL}_{\text {air }}=105+17.7 \log \frac{\mathrm{HP}_{\text {air }}}{\mathrm{N}}+15 \log \frac{\mathrm{N}}{6}, \mathrm{~dB} \operatorname{re} 10^{-12} \mathrm{~W}
$$

The C. W. Allen correlation gives the overall acoustic source strength as a function of shaft horsepower and the total pressure rise in inches of water as

$$
\mathrm{PWL}_{\text {air }}=93+10 \log (\mathrm{HP} \times \Delta \mathrm{p}), \mathrm{dB} \text { re } 10^{-12} \mathrm{~W} .
$$

In the following discussion the Peistrup-Wesler correlation will be used.

In order to apply this relationship to determine the acoustic source strength of a circulator in He and $\mathrm{CO}_{2}$ the operating conditions in He and $\mathrm{CO}_{2}$ must be translated to air, keeping the tip Mach number constant to ensure dynamic similarity. It will be assumed that the same circulator is used for both gases. In this case the difference in acoustic source strength can be expressed as

$$
\mathrm{PWL}_{\mathrm{He}}-\mathrm{PWL}_{\mathrm{CO}_{2}}=10 \log \frac{\rho_{\mathrm{He}} \mathrm{C}_{\mathrm{He}}^{3}}{\rho_{\mathrm{CO}_{2}} \mathrm{C}_{\mathrm{CO}}^{3}}, \mathrm{~dB}
$$


where $\rho_{\mathrm{He}\left(\mathrm{CO}_{2}\right)}=\mathrm{He}\left(\mathrm{CO}_{2}\right)$ gas density at circulator inlet conditions, $\mathrm{kg} / \mathrm{m}^{3}$, $\begin{aligned} & \mathrm{C}_{\mathrm{He}}\left(\mathrm{CO}_{2}\right)= \text { sound velocity in } \mathrm{He}\left(\mathrm{CO}_{2}\right) \text { at circulator inlet conditions, } \\ & \mathrm{m} / \mathrm{sec} .\end{aligned}$

Hence the acoustic source strength of a circulator operating in He at $940 \mathrm{~K}$ and $4.73 \times 10^{6} \mathrm{~Pa}$ is approximately $12 \mathrm{~dB}$ higher than that for the same circulator operating at the same tip Mach number in $\mathrm{CO}_{2}$ at $720 \mathrm{~K}$ and $1.07 \times 10^{6} \mathrm{~Pa}$ (MAGNOX conditions). This means that

$$
\frac{\mathrm{W}_{\mathrm{P}, \mathrm{He}}}{\mathrm{W}_{\mathrm{P}, \mathrm{CO}_{2}}}=15.8
$$

Table B-2 lists the real operating conditions for four primary coolant circulators of a different design and their acoustic source strength in $W$. This table clearly shows that the actual acoustic source strength of circulators operating in helium is significantly lower than the acoustic source strength of the Hinkley Point $\mathrm{CO}_{2}$ circulator. The acoustic efficiency, defined as

$$
n_{\mathrm{ac}}=\frac{\text { acoustic power }}{\text { mechanical shaft power }}
$$

appears to be 7 to 15 times lower for the circulators operating in helium than in $\mathrm{CO}_{2}$. Consequently, the sound pressure levels will also be lower in the than in $\mathrm{CO}_{2}$.

The acoustic energy generated by the circulators is propagated around the gas circuit and dissipated in the coolant gas itself and in the circuit structures. 
TABLE B-2

PRIMARY COOLANT CIRCULATOR OPERATING CONDITIONS

\begin{tabular}{|c|c|c|c|c|}
\hline & $\begin{array}{l}\text { Hinkley } \\
\text { Point A }\end{array}$ & \begin{tabular}{|c|} 
Fort St. Vrain \\
SC-HTGR
\end{tabular} & \begin{tabular}{|l} 
Lead Plant \\
SC-HTGR
\end{tabular} & GCFR \\
\hline Primary coolant & $\mathrm{CO}_{2}$ & $\mathrm{He}$ & $\mathrm{He}$ & $\mathrm{He}$ \\
\hline Mass flow, $\mathrm{kg} / \mathrm{sec}$ & 744 & 110 & 281 & 234 \\
\hline Volume flow, $\mathrm{m}^{3} / \mathrm{sec}$ & 58.5 & 32.2 & 67.1 & 44.8 \\
\hline Inlet pressure, $10^{6} \mathrm{~Pa}$ & 1.07 & 4.73 & 5.26 & 8.71 \\
\hline Inlet temperature, $\mathrm{K}$ & 447 & 667 & 593 & 593 \\
\hline Gas density at inlet, $\mathrm{kg} / \mathrm{m}^{3}$ & 12.9 & 3.41 & 4.19 & 5.22 \\
\hline Total pressure rise, $10^{6} \mathrm{~Pa}$ & 0.061 & 0.097 & 0.12 & 0.29 \\
\hline Circulator speed, rpm & 2,950 & 9,550 & 6,350 & 11,700 \\
\hline Shaft power, MW & 4.66 & 3.88 & 10.3 & 15.7 \\
\hline Number of rotor blades & 11 & 31 & 53 & 41 \\
\hline Rotor tip diameter, $\mathrm{m}$ & 1.57 & 0.69 & 1.09 & 0.72 \\
\hline Rotor hub diameter, m & - & 0.46 & 0.85 & 0.56 \\
\hline Tip speed, m/sec & 243 & 336 & 362 & 445 \\
\hline M tip & 0.70 & 0.22 & 0.25 & 0.31 \\
\hline Acoustic source strength, $W$ & 905 & 50 & 217 & 426 \\
\hline $\begin{array}{l}\text { Acoustic power/mech. } \\
\text { shaft power }\end{array}$ & $194 \times 10^{-6}$ & $13 \times 10^{-6}$ & $21 \times 10^{-6}$ & $27 \times 10^{-6}$ \\
\hline
\end{tabular}


The differences between $\mathrm{CO}_{2}$ and He as regards noise absorption or damping can be listed as follows:

1. The volumetric attenuation caused by viscous effects is given by

$$
\alpha=\frac{\omega^{2}}{2 \rho C^{3}}\left(\frac{4 \mu}{3}-\frac{K(\gamma-1)}{C_{p}}\right) \text {, }
$$

$$
\text { where } \begin{aligned}
\alpha & =\text { absorption coefficient, } \mathrm{m}^{-1}, \\
\omega & =\text { angular frequency, } \mathrm{rad} / \mathrm{s}, \\
\rho & =\text { gas density, } \mathrm{kg} / \mathrm{m}^{3}, \\
\mathrm{C} & =\text { velocity of sound, } \mathrm{m} / \mathrm{s}, \\
\mu & =\text { dynamic viscosity, } \mathrm{Pa} \cdot \mathrm{S}, \\
\mathrm{K} & =\text { thermal conductivity, } \mathrm{W} / \mathrm{mK}, \\
\gamma & =\text { ratio of specific heats, and } \\
\mathrm{C}_{\mathrm{p}} & =\text { specific heat at constant pressure, } \mathrm{J} / \mathrm{kgK} .
\end{aligned}
$$

Using the data of Table B-1 it can be shown that

$$
\alpha_{\mathrm{CO}_{2}, \text { MAGNOX }}=5.26 \times 10^{-14} \times \omega^{2}\left(\mathrm{~m}^{-1}\right)
$$

and

$$
\alpha_{\mathrm{He}, \mathrm{FSV}}=0.48 \times 10^{-14} \times \omega^{2}\left(\mathrm{~m}^{-1}\right)
$$

hence

$$
\alpha_{\mathrm{CO}_{2}, \text { MAGNOX }}=11 \times \alpha_{\mathrm{He}, \mathrm{FSV}} .
$$

For the same operating conditions ( $T$ and $p$ )

$$
\alpha_{\mathrm{CO}_{2}} \simeq 5 \quad \alpha_{\mathrm{He}}
$$

but for both coolants this volumetric attenuation is so small that it can be neglected. 
The high frequency acoustic absorption caused by relaxation processes can also be neglected for He because it is a monatomic gas.

2. A second acoustic absorption mechanism that can be neglected for both carbon dioxide and He is surface damping. It can be shown that acoustic energy is effectively transferred from the fluid to the confining surfaces into structural vibration energy only at resonant conditions.

3. The most important part of the acoustic energy absorption takes place at fluid boundaries with high velocity gradients. The attenuation depends on the gas properties, the flow Mach number, and the pressure drop. High dissipation occurs where the gas flow experiences large pressure drops, as, for example, in the GCFR core and the steam generator units.

It has been shown (Ref. B-4) that the modal damping loss factor caused by these viscous effects can be written as

$$
\begin{gathered}
n=\left(\frac{A}{V}\right)\left[1.4\left(\frac{U}{\omega}\right){ }^{1 / 2}\left(\frac{2}{3}+(\gamma-1) \operatorname{Pr}^{-1 / 2}\right)+\right. \\
0.027 \mathrm{R}_{\delta}^{\left.-0.23 \frac{U}{\omega}\right] \text { for } \omega>0.004 \frac{U}{\delta}} .
\end{gathered}
$$

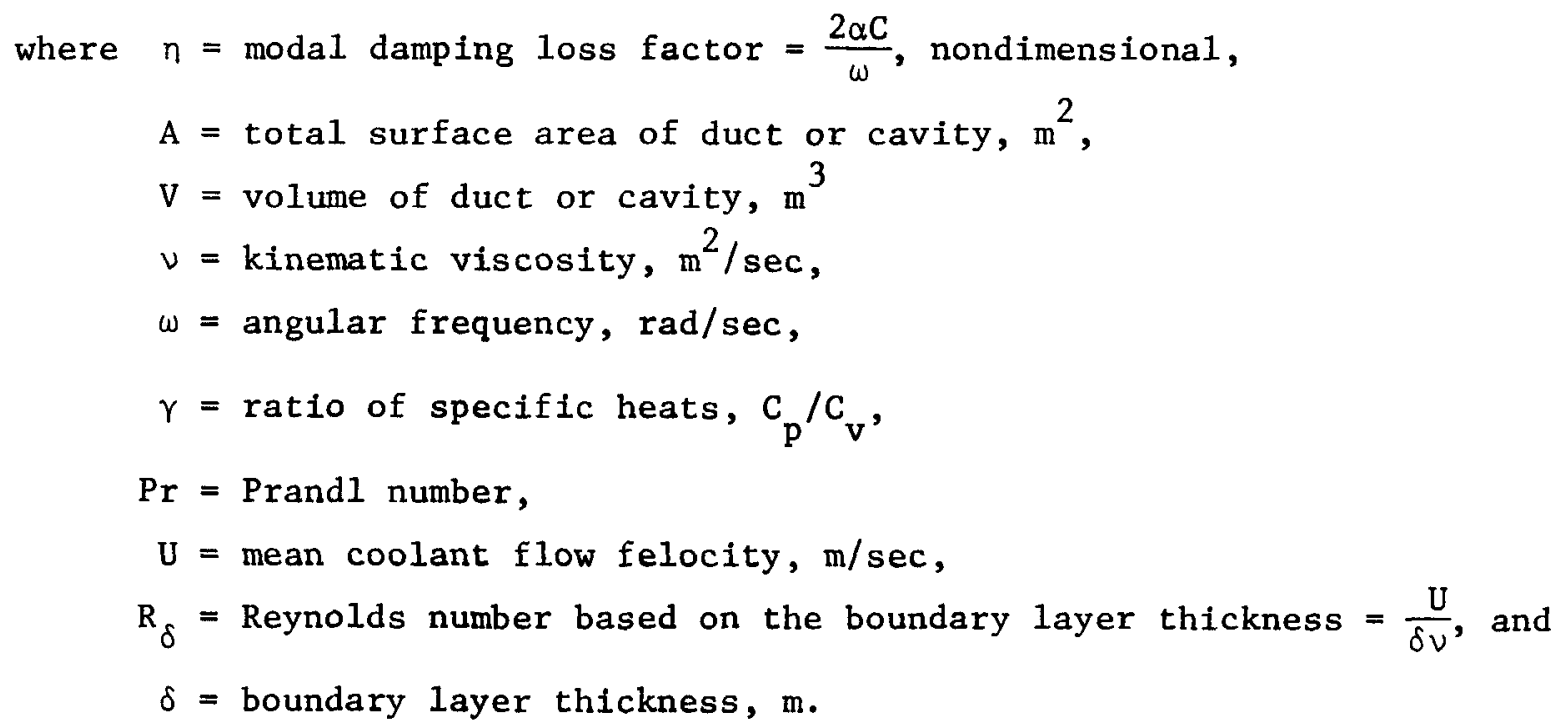


Substitution of the data of Table B-1 gives

$$
\begin{aligned}
& n_{\mathrm{He}, \mathrm{FSV}}=\frac{\mathrm{A}}{\mathrm{V}} \frac{0.008}{\sqrt{\omega}}+0.0021 \frac{\mathrm{U}^{0.77}}{\delta 0.23 \omega}, \\
& n_{\mathrm{He}, \mathrm{GCFR}}=\frac{\mathrm{A}}{\mathrm{V}} \frac{0.005}{\sqrt{\omega}}+0.0017 \frac{\mathrm{U}^{0.77}}{\delta^{0.23} \omega}, \\
& n_{\mathrm{CO}_{2}, \text { MAGNOX }}=\frac{\mathrm{A}}{\mathrm{V}} \frac{0.001}{\sqrt{\omega}}+0.0012 \frac{\mathrm{U}^{0.77}}{\delta^{0.23}} .
\end{aligned}
$$

All relationships for $\omega>0.004 \frac{\mathrm{U}}{\delta}$.

These relationships clearly show that the numerical value of the modal loss factor depends, besides the basic thermodynamic properties of the coolant, on the design of the reactor.

The response of the structure to the noise field in a reactor cavity is determined by the power flow between the acoustic modes of the cavity and the structural modes of the structure. Taking into account the frequency and spatial match between the structural and acoustical modes as well as the ratio of the acoustic impedance of the coolant to the structure's mechanical impedance, it can be shown (Ref. B-5) that the structural response $\overline{\left\langle v^{2}\right\rangle}$ can be written as

$$
\overline{\left\langle v^{2}\right\rangle}=\frac{\left\langle p^{2}\right\rangle}{\rho c^{2}} \cdot \frac{V}{N_{R}} \cdot \frac{R_{r a d}}{M^{*}}\left[\frac{R_{\text {mech }}+R_{r a d}}{N_{M}}\right]^{-1},
$$

where $\quad \overline{\left\langle v^{2}\right\rangle}=$ space and time averaged velocity of the structure, $\mathrm{m}^{2} / \mathrm{s}^{2}$,

$$
\begin{aligned}
\overline{\left\langle\mathrm{p}^{2}\right\rangle} & =\text { space and time averaged sound pressure, } \mathrm{Pa}^{2}, \\
\mathrm{~N}_{\mathrm{R}} & =\text { number of cavity modes, } \\
\mathrm{R}_{\text {rad }} & =\text { radiation resistance, } \mathrm{Nsec} / \mathrm{m}^{3},
\end{aligned}
$$




$$
\begin{aligned}
\mathrm{R}_{\text {mech }} & =\text { mechanical resistance, } \mathrm{Nsec} / \mathrm{m}^{3}, \\
\mathrm{~N}_{M} & =\text { number of interacting structural modes, } \\
\mathrm{M}^{*} & =\text { mass of the structure, } \mathrm{kg}, \text { and } \\
\rho, \mathrm{V} \text { and } \mathrm{c} & =\text { definitions stated previously. }
\end{aligned}
$$

This equation shows how changes in the acoustic medium will influence the structural response. Assuming the same plant design, and assuming incorrect1y the same sound pressure spectrum, the use of He at Fort St. Vrain conditions instead of $\mathrm{CO}_{2}$ at MAGNOX conditions results in

1. A reduction of the cavity modal density by a factor of $\sim 80$

2. A reduction of the acoustic energy density $\overline{\left\langle p^{2}>/ \rho c^{2}\right.}$ by approximately $75 \%$ which results, taking into account point 1 , in an approximately 20 times higher average acoustic modal energy than for $\mathrm{CO}_{2}$ at the same sound pressure

3. A modification of the coupling between the acoustic modes and the structure, $\mathrm{R}_{\mathrm{rad}}$.

$$
R_{\text {rad }}=A \rho c \sigma,
$$

$$
\text { where } \begin{aligned}
\mathrm{A} & =\text { surface area, } \mathrm{m}^{2}, \\
\sigma & =\text { radiation efficiency, } \\
\rho & =\text { gas density }, \mathrm{kg} / \mathrm{m}^{3}, \text { and } \\
c & =\text { velocity of sound, } \mathrm{m} / \mathrm{s} .
\end{aligned}
$$

This equation also shows that the change in response per unit sound pressure for a particular component depends on the ratio $R_{\text {mech }} / R_{\text {rad }}$. Figures $B-1$ and B-2 show the variation of $R_{\text {rad }}$, $R_{\text {mech }}$, and $\eta_{\text {rad }}$ for He and $\mathrm{CO}_{2}$ for a flat panel, surface area $6 \mathrm{~m}^{2}$, plate thickness $5 \mathrm{~mm}$, and $n=0.034$. The actual values of these variables depend on the way in which the panels have been mounted in the reactor cavities. However, the curves show the general trend. Figure B-3 gives the ratio of response per unit sound pressure for He and 


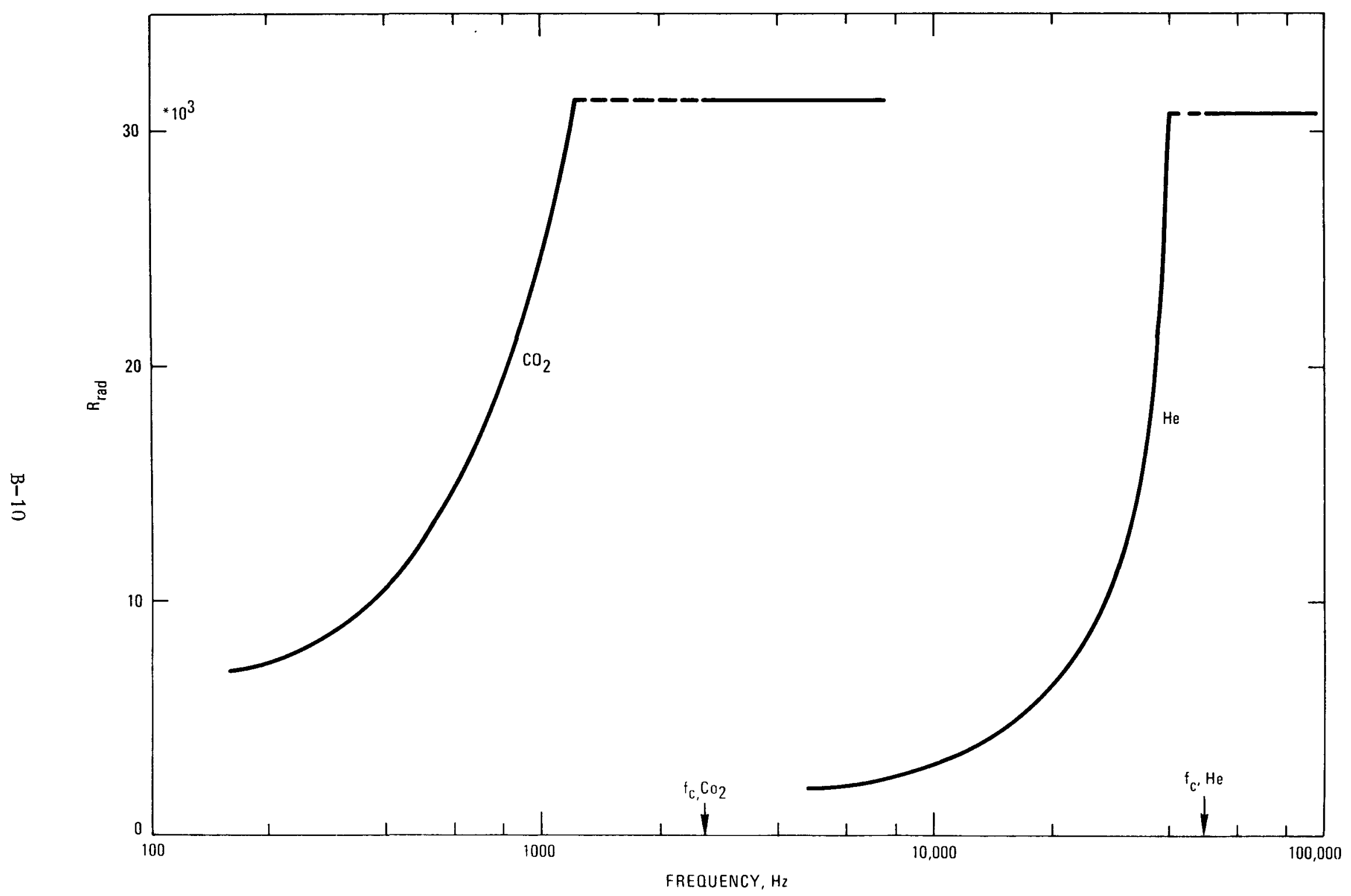

Fig. B-1. $R_{\text {rad }}$ as a function of frequency for a flat $6 \mathrm{~m}^{2}, 0.005-\mathrm{m}-$ thick plate in $\mathrm{He}$ and $\mathrm{CO}_{2}, \eta=0.034$ 


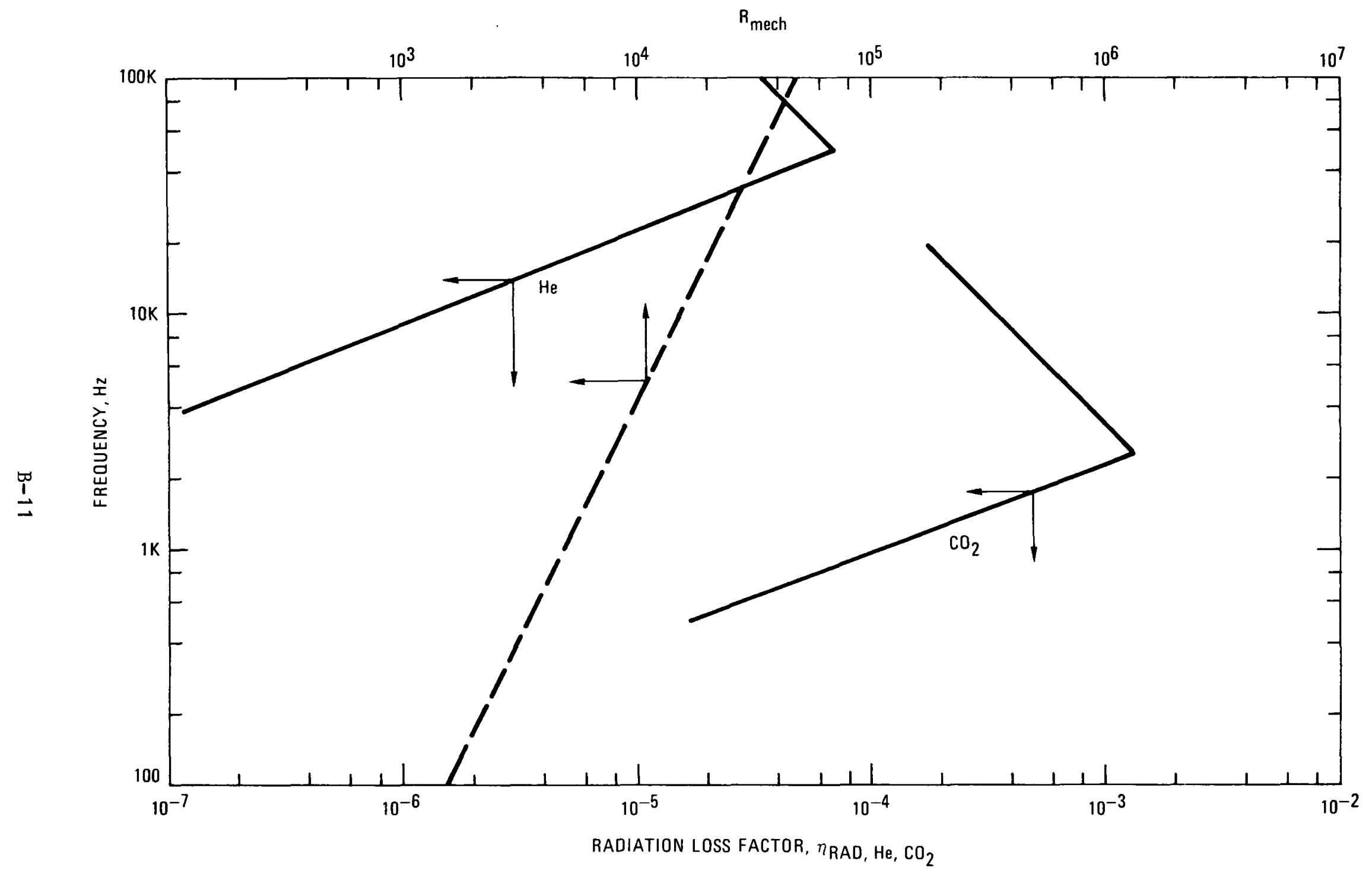

Fig. B-2. $\quad R_{\text {mech }}$ and $n_{\text {rad }}$ as a function of frequency for a flat plate in He and $\mathrm{CO}_{2}$ 


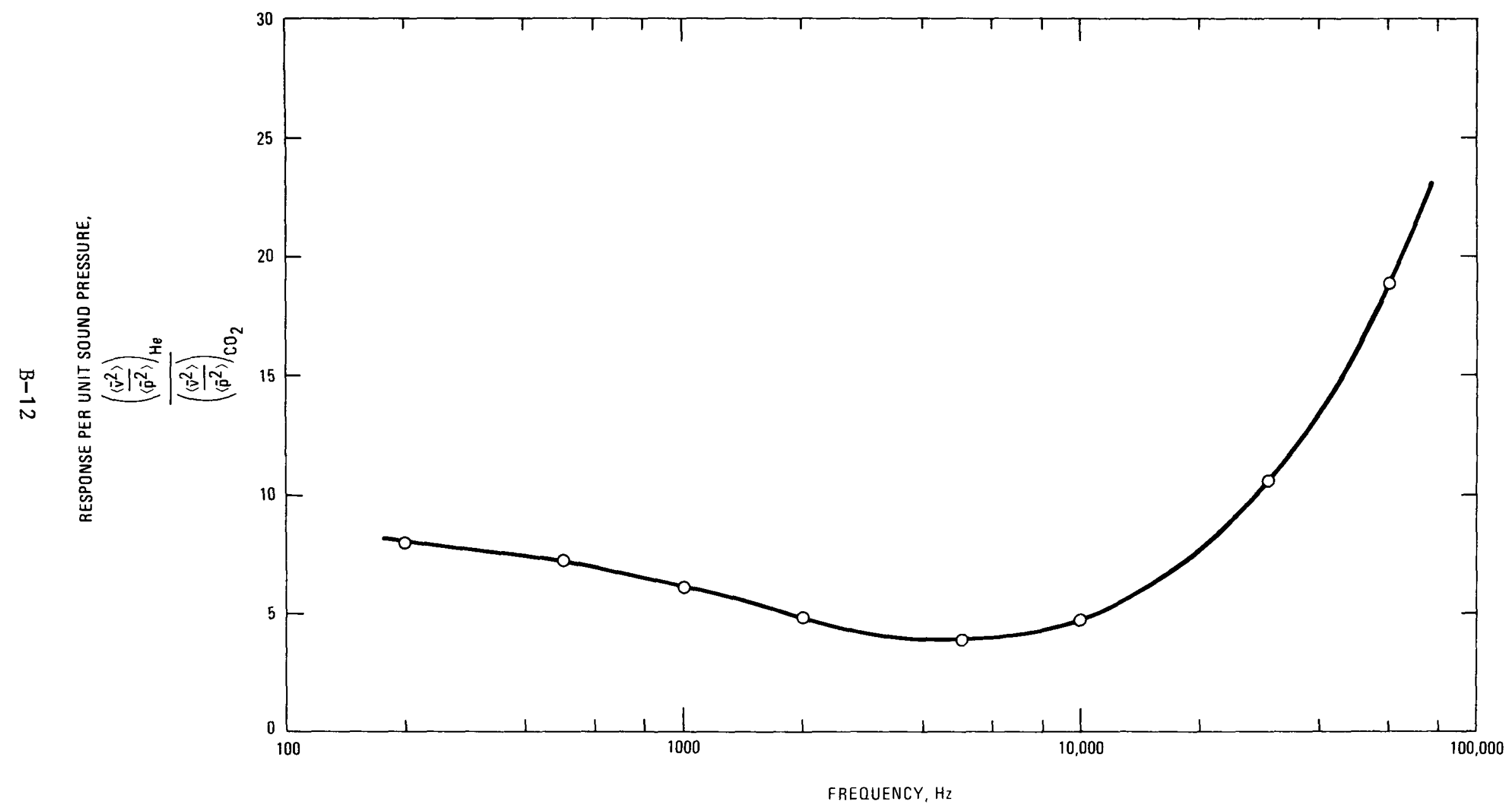

Fig. B-3. Relative response per unit sound pressure for a flat plate in He and $\mathrm{CO}_{2}$ 
$\mathrm{CO}_{2}$ as a function of the frequency. It must be stressed again that the sound pressure levels in a He system will be significantly lower than the sound pressure levels in a $\mathrm{CO}_{2}$ system and that consequently, the resulting dynamic loads will be less than expected on the basis of this highly simplified theory.

To summarize, it can be stated that the response of a structure or component in $\mathrm{CO}_{2}$ or He depends on

1. The acoustic power generated

2. The distribution of the acoustic energy over the system

3. The interaction between the acoustic field and the structure or component.

Although the resulting dynamic component stresses are difficult to predict, a preference for He seems to be justified.

Flow-Induced Vibrations

According to Ref. 1, the nondimensional variables that prove to be useful in describing the elastic vibrations of a structure in subsonic flow are

1. The fineness ratio, $\ell / D$

2. The reduced velocity, U/fD

3. The dimensionless amplitude, A/D

4. The mass ratio, $\mathrm{m} / \rho \mathrm{D}^{2}$

5. The Reynolds number, UD/v

6. The damping factor, $\zeta$ 
where $\ell=$ length of the obstacle, $m$,

$\mathrm{D}=$ width of the obstacle, $\mathrm{m}$,

$\mathrm{U}=$ primary coolant free stream velocity, $\mathrm{m} / \mathrm{s}$,

$\mathrm{f}=$ frequency of the vibration, $\mathrm{Hz}$,

$A=$ amplitude of the vibration, $\mathrm{m}$,

$\mathrm{m}=$ mass per unit length, $\mathrm{kg} / \mathrm{m}$,

$\rho=$ fluid density, $\mathrm{kg} / \mathrm{m}^{3}$,

$\nu=$ kinematic viscosity, $\mathrm{m}^{2} / \mathrm{s}$, and

$\zeta=$ damping factor or damping ratio equal to the energy dissipated per cycle divided by $4 \pi$ times the total energy of the structure.

Although for $\mathrm{CO}_{2}$-cooled reactors the Mach number is in general higher than that for helium-cooled reactors, compressibility effects can be neglected in both cases.

In addition to the fluid parameters, flow-induced vibration phenomena depend on conditions such as the fluid velocity, pressure, temperature, density, and turbulence intensity; on the geometry of the vibrating components, and the flow pattern around these components. The latter depends to a great extent on the location and shape of components and structures upstream and around the component studied. Depending on the natural frequencies of the adjacent structures, they can be regarded either as rigid or flexible.

The above indicates that again the choice of the primary coolant influences the structural requirements of the reactor and vice versa, and that the fluid mechanical descriptions are complex. Often no exact solutions are available. As a more detailed analysis is beyond the scope of this report, we have to content ourselves with one general statement: the higher the ratio of fluid density to structural density, the greater the mass ratiothe lower the reduced damping, and the greater the chance for flow-induced vibration phenomena.

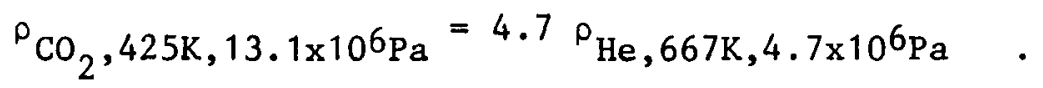




\section{REFERENCES}

B-1. Melese-d'Hospital, G., and P. Fortescue, "Thermodynamic Comparison of Gas Coolants for Nuclear Reactors," Proc. Inst. Mech. Engrs. V. 181, pt 31, p. 16. 1966-1967.

B-2. Peistrup, F. C., and J. E. Wesler, "Noịe of Ventilating Fans," J. Acoustica1 Soc. Am. 25, No. 2, 322-326 (1953).

B-3. Allen, C. H., "Noise Control in Ventilation Systems," Chapter 21 in Noise Reduction, L. L. Beranek, (ed.), McGraw-Hill Book Co., New York, 1960.

B-4. Burton, T. E., "Vibration of HTGR Plates and Shells," General Atomic Report GA-A13942, Chapter 7, 1977.

B-5. Whitton, P. N., and W. J. Hammill, "Vibration response of Reactor Components in Helium, Carbon Dioxide, and Air," Paper E5/6, 2nd SMIRT Conference, Berlin, 1973. 